\title{
EFFECT OF PARENTAL HISTORY OF HYPERTENSION ON HEART RATE AND BLOOD PRESSURE AT REST AND AFTER EXERCISE
}

Dabade Sheetal Kuldeep ${ }^{1}$, Dabade Kuldeep J²

\section{HOW TO CITE THIS ARTICLE:}

Dabade Sheetal Kuldeep, Dabade Kuldeep J. "Effect of Parental History of Hypertension on Heart Rate And Blood Pressure At Rest And After Exercise". Journal of Evolution of Medical And Dental Sciences 2013; Vol2, Issue 50, December 16; Page: 9753-9760.

ABSTRACT: BACKGROUND: Hypertension (HTN) is a common public health challenge. Early detection and appropriate treatment is the solution to this problem. Normotensives with parental history of hypertension have higher risk of developing this disorder. Such normotensives have greater cardiovascular reactivity to exercise. OBJECTIVES: To identify abnormal heart rate (HR) and blood pressure (BP) responses during exercise recovery in young adult normotensives with and without parental history of hypertension. MATERIAL AND METHODS: The present study was conducted in the clinical laboratory of Department of Physiology, MNR Medical College, Sangereaddy, Andhra Pradesh during May 25th 2011 to July 25th 2011 to observe the cardiovascular response (HR \& BP) to exercise in healthy young adults using Harvard step test and to compare the influence of parental history of hypertension on it. 100 healthy young adults were selected in the age group of 18-22 year from the student population of our college. They were divided into 2 major groups (each major group consisting of 50 subjects) based on history of hypertension in their parents. The students having parental history of hypertension in at least one parent were taken in study group. Those students having both normotensive parents were taken as controls for comparison. Each major group was further divided into 2 minor groups based on gender (each minor group consisting of 25 subjects).Statistical Analysis: Data analysis between the groups was done with using SPSS software for Windows, Version 15. Independent-Sample T-test was used to find significant difference between the subjects with and without parental history of HTN. Statistical significance was set at $p<0.05$. RESULTS AND CONCLUSION: In male subjects having family history of hypertension the HR at rest and at $3^{\text {rd }}, 6^{\text {th }}, 9^{\text {th }} \& 12^{\text {th }}$ minute of exercise recovery; immediate recovery systolic blood pressure (SBP) and diastolic blood pressure (DBP) at $3^{\text {rd }}$ minute of recovery were significantly higher compared to age and sex matched subjects without family history of hypertension. Whereas in females only HR at the immediate recovery period was significantly higher in study subjects having parental history of hypertension compared to controls.

KEY WORDS: hypertension, cardiovascular reactivity, normotensive, parental history

INTRODUCTION: Hypertension is probably the most important public health problem. It is common, asymptomatic and often leads to lethal complications leading to premature death due to heart disease, stroke and renal failure. The younger the patient when hypertension is first noted, the greater is the reduction in life expectancy if it is left untreated. ${ }^{1}$ Hence we need tests that can detect susceptible individuals at an early age who could be future hypertension victims. There is high prevalence of hypertension in children having family history of hypertension. ${ }^{2}$ Offspring of hypertensive parents show sympathetic overactivity. ${ }^{3}$ 


\section{ORIGINAL ARTICLE}

Their exaggerated response to constrictor stimulation precedes development of high blood pressure. ${ }^{4}$ The prehypertensive state can be unmasked by abnormal cardiovascular reactivity to various forms of stress like psychological stress, cold water immersion, or exercise stress tests. Among all these tests, exercise stress tests are well known and have been reported to be a good predictor of hypertension. ${ }^{5}$ However its reliability as a test for prediction of hypertension onset is still being discussed. Hence, in the present study an attempt is made to compare the heart rate and blood pressure at rest \& after physical exercise using Harvard step test in healthy young adults having parental history of hypertension with those having normotensive parents.

\section{AIMS \& OBJECTIVES:}

1) To study the heart rate and blood pressure at rest and after physical exercise in healthy young adults(18-22 yrs).

2) To compare the exercise stress reactivity (heart rate and blood pressure response) of healthy young adults having parental history of hypertension with the age and gender matched controls not having such history.

MATERIALS AND METHODS: The present study has been conducted to observe the cardiovascular response (heart rate and blood pressure) to exercise in healthy young adults using Harvard step test and to compare the influence of parental history of hypertension on it. The study was conducted in the clinical laboratory of Department of Physiology, MNR Medical College, Sangereaddy, Andhra Pradesh during May 25th 2011 to July 25th 2011. After thorough examination, 100 healthy young adults were selected in the age group of 18-22 year from the student population of our college. The students were divided into 2 major groups (each major group consisting of 50 subjects) based on history of hypertension in their parents. The students having parental history of hypertension in at least one parent were taken in study group. Those students having both normotensive parents were taken as controls for comparison. Each major group was further divided into 2 minor groups based on gender (each minor group consisting of 25 subjects).

\section{Inclusion criteria:}

1. Healthy asymptomatic young adults (males and females) between 18-22 years of age.

2. Non-smokers

3. Normal Body Mass Index (BMI) - 18.5-24.9 kg/m2

\section{Exclusion criteria:}

1. Any acute illness

2. Diabetes Mellitus

3. Anti-hypertensive medication

4. History of chest pain, breathlessness, orthopnoea

5. Handicapped individuals

6. Trained subjects (sports \& yoga)

\section{Instruments:}

1. Harvard step: Harvard step used in our study was a wooden bench with two steps. Each step has a height of twelve inches, a width of eighteen inches and a breadth of twenty four inches. 


\section{ORIGINAL ARTICLE}

The whole step was three feet long and one and a half feet broad. It was used for the exercise called as Harvard step test.

2. Automatic blood pressure monitor: The blood pressure monitor AT-987 (M-1) was a fully automatic, digital blood pressure measuring device for use on the upper arm which enables very fast and reliable measurement of heart rate and blood pressure by oscillometric methods of measurement. The device offers a very high accuracy of measurement and has been clinically tested. The automated blood pressure apparatus was calibrated by comparing with the mercury sphygmomanometer which was the gold standard for blood pressure measurement. A rubber $\mathrm{Y}$ tube was taken and one limb of the $\mathrm{Y}$ tube was connected to the automated blood pressure apparatus and another limb was connected to a mercury sphygmomanometer. The automated blood pressure apparatus was switched on. A steady pressure was applied on the cuff. The corresponding readings on the automated blood pressure apparatus and the sphygmomanometer were read. Correlation of both readings was found to be 0.8 .

3. Stadiometer: It was used to measure height \& weight. Weight was measured to the nearest 100 grams and height was measured to the nearest $0.1 \mathrm{~cm}$.

4. Stop watch: It was used to record timing in seconds during the procedure.

Method of collection of data:The volunteers selected for the study were explained about the purpose of the study. They were instructed to fill up a proforma giving details regarding parental history of hypertension. Accordingly, they were divided into study and controlgroup. All the data was collected during morning hours between 10 am to 12 noon. First, physical examination was done and base line characteristics of all subjects were recorded which includes age, weight, height, body mass index (weight /Height squaremeters). Written informed consent was taken.The subjects were instructed about the procedure in brief and the Harvard step test exercise was actually demonstrated before them in order to allay apprehension. It is a simple 3 minute step test using a plat form of 12 inch height. Subjects were instructed to step up and step down on the platform with a step frequency of 30 steps per minute. Heart rate and blood pressure were recorded by above mentioned digital monitor that displays heart rate as well as blood pressure. Recording was done in left arm in sitting posture at rest, immediately after exercise and at 3, 6, 9, 12 minute during recovery phase. These parameters at rest and during recovery phase were compared between study and control group after matching with age and gender.

The data was collected in a specially designed case recording form, and subjected to the statistical analysis.

Statistical Analysis:The study involves dividing the subjects into four groups, collection of data on heart rate, systolic blood pressure, and diastolic blood pressure in each group. Data analysis between the groups was done on computer using SPSS software for Windows, Version 15. Independent-Sample T-test was used to find significant difference between the subjects with and without parental history of hypertension. Statistical significance was set at $\mathrm{p}<0.05$. 


\section{ORIGINAL ARTICLE}

Observations \& results:Table 1 shows male subjects in the two groups were comparable with respect to mean age, height, weight and body mass index ( $p>0.05)$. Mean resting heart rate was significantly much higher in the group with family history of hypertension. There was no significant difference in resting systolic blood pressure and diastolic blood pressure between the two groups.

Table 2 states that heart rate recorded after exercise was significantly higher in male subjects havingparental history of hypertension compared to their counter parts having normotensive parents during throughout the recovery phase except at immediate recovery period. Systolic blood pressure after immediate exercise and diastolic blood pressure at 3rd minute of recovery were also significantly higher in them.

Table 3 shows female subjects in the two groups were comparable with respect to mean age, height, weight and body mass index ( $>0.05)$. Resting heart rate, Systolic blood pressure and diastolic blood pressure also did not show statistically significant difference.

Table 4 states that heart rate were comparable in both the groups of female subjects throughout the recovery phase except immediate recovery heart rate which was significantly higher in the group having parental history of hypertension. Both systolic blood pressure and diastolic blood pressure also did not show statistically significant difference during throughout the recovery period.

DISCUSSION: Prevention of hypertension remains elusive, and efforts must be continued to make its primary prevention a realistic public health goal. Studies suggest that exaggerated blood pressure response to exercise in high-risk population correlates well with development of subsequent hypertensionon long-term follow-up. ${ }^{6}$

In an attempt to identify forerunners of hypertension, we compared the heart rate and blood pressure at rest, during different stages of recovery after exercise in normotensive young adult subjects having history of hypertension in one or both parents with the age and sex matched normotensive subjects having both normotensive parents.

Our most important finding was that those with a family history of hypertension had a higher heart rate response during several stages of recovery of exercise. In male subjects, in addition, systolic blood pressure immediately after exercise and diastolic blood pressure at $3^{\text {rd }}$ minute of recovery were also significantly higher in those with family history of hypertension.

Our observations match with other studies of similar design conducted by Molineux D and Steptoe $\mathrm{A}^{7}$, Biagini $\mathrm{M}$ and Brassetti $\mathrm{B}^{8}$, Radice $\mathrm{M}$ and coworkers ${ }^{9}$.

Various theories have been proposed for the exaggerated heart rate and blood pressure response to exercise in subjects with parental history of hypertension. Julius S and Schork MA ${ }^{10}$ suggested that those who have a positive family history of hypertension frequently exhibit hyperactive sympathetic nervous system. The consequences of sympathetic nervous system stimulation are peripheral vasoconstriction, an increase in heart rate, and a resultant increase in peripheral vascular resistance with rise in systemic blood pressure. Mehta SK and coworkers ${ }^{11}$ suggested that independent of blood pressure levels, the subjects with parental hypertension have a reduced proximal and distal arterial compliance. The lower arterial compliance can result in an exaggerated blood pressure response during exercise. Chi Young Shim and his colleagues ${ }^{12}$ in a recent study compared subjects with an exaggerated blood pressure response to exercise with age and gender matched control subjects with normal blood pressure reactivity and observed that an 


\section{ORIGINAL ARTICLE}

exaggerated blood pressure response to exercise was associated with augmented rise of angiotensin II during exercise.

Resting heart rate and blood pressure (only heart rate was statistically significant) were higher in subject group having family history of hypertension. Defining hypertension has been, and still continues to be an evolving process. Recently, the seventh report of Joint National Committee (JNC VII $)^{3}$ suggested normal blood pressure as $<120 / 80 \mathrm{mmHg}$. Systolic blood pressure between 120-139 mm of $\mathrm{Hg}$ and diastolic blood pressure between 80-89 $\mathrm{mm}$ of $\mathrm{Hg}$ has been classified as prehypertension. Comparatively higher heart rate \& blood pressure levels in our study subjects may reflect their genetic predisposition which may gradually drift in prehypertensive stage and later in hypertensive stage if timely preventive measures were not taken.

The significantly higher mean blood pressure values in certain stages of exercise recovery (immediate recovery systolic blood pressure and diastolic blood pressure at $3^{\text {rd }}$ minute of recovery) in male subjects are consistent with the findings from other studies ${ }^{8,11}$. Biagini $\mathrm{M}$ and Brassetti $\mathrm{B}^{8}$ showed subjects with family history of hypertension showed significantly slower recovery of systolic blood pressure. Mehta SK and his colleagues ${ }^{11}$ found higher diastolic blood pressure during recovery in their study subjects. Immediate post exercise period is associated with a withdrawal of sympathetic tone and a rebound increase in vagal tone; it is possible that abnormalities of autonomic control could extend into the early recovery phase of exercise resulting in elevated recovery blood pressure in those at risk of hypertension.

These response patterns in high-risk group could represent a generally stable characteristic consisting of an impaired cardiovascular adjustment to exercise, which is not apparent at rest and may be unmasked only during exercise. This may indicate a greater risk for development of hypertension in such subjects. Frequently, regular hemodynamic stress in high-risk subjects with exaggerated blood pressure response during exercise could constitute an additional risk factor for the development of left ventricular hypertrophy and accelerated target organ damage.

Our study has shown gender differences in cardiovascular parameters at rest and also after exercise. These gender differences may help in interpreting exercise responses more accurately stratified by gender.

Limitations of our study: In our study blood pressure recording was done using digital manometer. We could not record blood pressure changes during exercise as the instrument was movement sensitive. Measurements recorded directly using an intra-arterial cannula is more accurate. But for general use it is desirable that this be done noninvasively like in our study.

CONCLUSION: In our study, healthy young adults with family history of hypertension showed significantly increased tendency for abnormal heart rate and blood pressure response to exercise test. In addition to resting blood pressure recordings, heart rate and blood pressure response after an exercise challenge can be a good tool to stratify them further for future monitoring.

The comparatively higher heart rate and blood pressure response in normotensive subjects may reflect the adverse influence of their parental history of hypertension. It may be due to the failure to reduce total peripheral resistance adequately during exercise as a result of initial structural vascular changes which would pre-date the tonic elevation in the blood pressure. The 


\section{ORIGINAL ARTICLE}

skeletal muscle vasodilator capacity is limited and the dynamic exercise blood pressure response may be exaggerated in normotensives with genetic risk of hypertension.

The reported data could be used by clinicians to interpret more accurately the significance of exaggerated blood pressure response during exercise in a subject of a specific sex and may permit investigators to define and interpret blunted heart rate, systolic blood pressure and diastolic blood pressure decline after exercise in statistical terms stratified by gender.

As for abnormal heart rate and blood pressure response translating into future hypertension, long-term follow-up studies may provide the answer.

\section{REFERENCES:}

1. Kotchen TA. Hypertensive vascular disease. In: Fauci AS, Braunwald E, Kasper DL, Hauser SL, Longo DL, Jameson JL, et al, editors. Harrison's principles of internal medicine. 17thEd. New York: McGraw-Hill; 2008. p. 1549-62.

2. N.K. Anand, LalitTandon. Prevalence of hypertension in school going children. Indian pediatr 1996May; 33: 377-381.

3. Charles Perini, Franco B. Muller, UdoRauchfleisch, Raymond Battegay, Viktor Hobi, Fritz R. Buhler. Psychosomatic factors in borderline hypertensive subjects and offspring of hypertensive parents. Hypertension1990; 16: 627-634.

4. A.E. Doyle, J.R.E. Fraser. Essential hypertension and inheritance of vascular reactivity. Lancet 1961; Sep 2: 509-511.

5. M. Radice, C. Alli, F. Avanzini, M. Di Tullio, G. Marriotti, E. Taioli et al. Role of blood pressure response to provocative tests in the prediction of hypertension in adolescent. Eur Heart J. 1985; 6(6): 490-496.

6. Miyai N, Arita M, Miyashita K, Morioka I, Shiraishi T, Nishio I. Blood pressure response to heart rate during exercise test and risk of future hypertension. Hypertension 2002; 39:761-6.

7. Molineux D, Steptoe A. Exaggerated blood pressure responses to submaximal exercise in normotensive adolescents with a family history of hypertension. J Hypertens1988 May; 6(5):361-5.

8. Biagini M, Brassetti B, Pierangeli L, Roscio G, Arrabito B. Blood pressure response to exercise in young subjects with and without parental history of hypertension. J HumHypertens1996; 10(3):S81-3.

9. Radice M, Alli C, Avanzini F, Di Tullio M, Mariotti G, Taioli E, et al. Role of blood pressure response to provocative tests in the prediction of hypertension in adolescents. Eur Heart J 1985;6(6):490-6.

10. Julius S, Schork MA. Predictors of hypertension. Ann NY AcadSci1978; 304:38-58.

11. Mehta SK, Super DM, Anderson RL, Harcar-Sevcik RA, Babjak M, Liu X, et al. Parental hypertension and cardiac alterations in normotensive children and adolescents. Am Heart J 1996 Jan; 131(1):81-8.

12. Palatini P. Exaggerated blood pressure response to exercise: pathophysiologic mechanisms and clinical relevance. J Sports Med Phys Fitness 1998 Mar; 38(1):1-9. 


\section{ORIGINAL ARTICLE}

\begin{tabular}{|c|c|c|c|}
\hline $\begin{array}{c}\text { Baseline } \\
\text { Characteristics }\end{array}$ & $\begin{array}{l}\text { Males without } \mathrm{F} / \mathrm{H} \text { of } \\
\text { hypertension } \mathrm{n}=25\end{array}$ & $\begin{array}{c}\text { Males with } \mathrm{F} / \mathrm{H} \text { of } \\
\text { Hypertension } \mathrm{n}=25\end{array}$ & $\mathrm{p}$ value \\
\hline Age (years) & $19.76 \pm 0.18$ & $19.32 \pm 0.20$ & 0.0593 \\
\hline Height (meters) & $1.75 \pm 0.06$ & $1.67 \pm 0.01$ & 0.1283 \\
\hline Weight (kg) & $57.44 \pm 1.17$ & $58.44 \pm 1.61$ & 0.3090 \\
\hline BMI $\left(\mathrm{kg} / \mathrm{m}^{2}\right)$ & $20.22 \pm 0.30$ & $21.08 \pm 0.54$ & 0.0848 \\
\hline Resting HR(beats/min) & $78.96 \pm 2.15$ & $88.64 \pm 1.94$ & $0.0008^{* * *}$ \\
\hline Resting SBP(mm Hg) & $125.8 \pm 1.66$ & $124.2 \pm 1.92$ & 0.2664 \\
\hline Resting DBP(mm Hg) & $84.16 \pm 3.10$ & $82.92 \pm 1.84$ & 0.3664 \\
\hline
\end{tabular}

Note: Results are expressed as mean \pm SD * significant

Table No. 2: Post exercise test (Recovery phase) characteristics of male subjects.

\begin{tabular}{|c|c|c|c|c|}
\hline \multicolumn{2}{|c|}{$\begin{array}{c}\text { Recovery } \\
\text { Characteristics }\end{array}$} & $\begin{array}{l}\text { Males without } F / H \text { of } \\
\text { hypertension } n=25\end{array}$ & $\begin{array}{l}\text { Males with F/H of } \\
\text { hypertension } n=25\end{array}$ & $P$ value \\
\hline \multirow{3}{*}{$\begin{array}{l}\text { Recovery } \\
\text { immediate }\end{array}$} & HR & $108.2 \pm 2.33$ & $112.5 \pm 3.89$ & 0.3462 \\
\hline & SBP & $144.6 \pm 2.73$ & $152.6 \pm 3.07$ & 0.0289* \\
\hline & DBP & $82.92 \pm 3.10$ & $84.16 \pm 1.84$ & 0.3664 \\
\hline \multirow{3}{*}{ Recovery3min } & HR & $91.64 \pm 2.41$ & $101.3 \pm 3.05$ & $0.0082^{* *}$ \\
\hline & SBP & $127.0 \pm 1.44$ & $127.4 \pm 2.31$ & 0.4305 \\
\hline & DBP & $75.32 \pm 1.84$ & $82.92 \pm 1.26$ & $0.0007^{* * *}$ \\
\hline \multirow{3}{*}{ Recovery6min } & HR & $89.56 \pm 2.22$ & $97.28 \pm 2.92$ & $0.0205^{*}$ \\
\hline & SBP & $120.0 \pm 1.63$ & $120.8 \pm 2.95$ & 0.4115 \\
\hline & DBP & $74.44 \pm 1.53$ & $75.24 \pm 1.92$ & 0.3733 \\
\hline \multirow{3}{*}{ Recovery9min } & HR & $89.16 \pm 2.10$ & $97.92 \pm 2.76$ & $0.0076^{* *}$ \\
\hline & SBP & $119.8 \pm 1.97$ & $120.8 \pm 2.73$ & 0.3930 \\
\hline & DBP & $72.72 \pm 1.64$ & $73.72 \pm 1.81$ & 0.3421 \\
\hline \multirow{3}{*}{ Recovery12min } & HR & $88.72 \pm 1.92$ & $98.72 \pm 2.48$ & $0.0013^{* *}$ \\
\hline & SBP & $120.6 \pm 2.12$ & $121.6 \pm 2.27$ & 0.3697 \\
\hline & DBP & $74.08 \pm 3.19$ & $75.24 \pm 2.19$ & 0.4147 \\
\hline
\end{tabular}

Note: Results are expressed as mean \pm SD *- significant

\begin{tabular}{|l|l|l|l|}
\hline \multicolumn{4}{|c|}{ Table No. 3: Baseline characteristics of female subjects } \\
\hline $\begin{array}{l}\text { Baseline } \\
\text { Characteristics }\end{array}$ & $\begin{array}{l}\text { Females without F/H of } \\
\text { hypertension n=25 }\end{array}$ & $\begin{array}{l}\text { Females with F/H of } \\
\text { hypertension n=25 }\end{array}$ & p value \\
\hline Age (years) & $19.28 \pm 0.20$ & $19.76 \pm 0.18$ & 0.0566 \\
\hline Height (meters) & $1.582 \pm 0.012$ & $1.58 \pm 0.01$ & 0.4622 \\
\hline Weight $(\mathrm{kg})$ & $51.16 \pm 1.03$ & $51.76 \pm 1.19$ & 0.7056 \\
\hline BMI $\left(\mathrm{kg} / \mathrm{m}^{2}\right)$ & $20.62 \pm 0.37$ & $20.96 \pm 0.38$ & 0.2628 \\
\hline Resting HR(beats $/ \mathrm{min})$ & $80.84 \pm 2.35$ & $82.92 \pm 2.23$ & 0.2625 \\
\hline Resting SBP(mm Hg) & $108.1 \pm 1.41$ & $106.2 \pm 1.77$ & 0.2105 \\
\hline Resting DBP(mm Hg) & $66.76 \pm 1.27$ & $66.36 \pm 1.88$ & 0.4307 \\
\hline
\end{tabular}




\begin{tabular}{|c|c|c|c|c|}
\hline \multicolumn{2}{|c|}{ Recovery Characteristics } & \multirow{2}{*}{$\begin{array}{c}\begin{array}{c}\text { Females without } \mathbf{F} / \mathbf{H} \\
\text { of hypertension } \\
\mathbf{n}=\mathbf{2 5}\end{array} \\
123.3 \pm 3.75\end{array}$} & \multirow{2}{*}{$\begin{array}{c}\begin{array}{c}\text { Females with } \mathbf{F} / \mathbf{H} \text { of } \\
\text { hypertension } \\
\mathbf{n}=\mathbf{2 5}\end{array} \\
133.6 \pm 3.75\end{array}$} & \multirow{2}{*}{$\begin{array}{l}\text { P value } \\
0.0284^{*}\end{array}$} \\
\hline \multirow{3}{*}{ Recoveryimmediate } & HR & & & \\
\hline & SBP & $135.2 \pm 2.93$ & $135.2 \pm 1.47$ & 0.1925 \\
\hline & DBP & $78.68 \pm 1.89$ & $79.64 \pm 2.09$ & 0.3677 \\
\hline \multirow{3}{*}{ Recovery3min } & HR & $99.20 \pm 3.21$ & $101.4 \pm 2.54$ & 0.3004 \\
\hline & SBP & $117.8 \pm 2.13$ & $117.8 \pm 2.14$ & 0.4895 \\
\hline & DBP & $66.56 \pm 2.21$ & $69.72 \pm 1.72$ & 0.1581 \\
\hline \multirow{3}{*}{ Recovery6min } & HR & $96.36 \pm 2.77$ & $97.48 \pm 2.45$ & 0.3818 \\
\hline & SBP & $107.10 \pm 2.64$ & $110.0 \pm 1.79$ & 0.1698 \\
\hline & DBP & $63.36 \pm 2.74$ & $68.12 \pm 2.90$ & 0.0982 \\
\hline \multirow{3}{*}{ Recovery9min } & HR & $94.28 \pm 2.79$ & $95.84 \pm 1.84$ & 0.3216 \\
\hline & SBP & $104.7 \pm 3.2$ & $107.6 \pm 1.87$ & 0.2053 \\
\hline & DBP & $65.04 \pm 3.93$ & $69.20 \pm 1.66$ & 0.1868 \\
\hline \multirow{3}{*}{ Recovery 12 min } & HR & $95.32 \pm 2.40$ & $97.32 \pm 2.06$ & 0.2658 \\
\hline & SBP & $104.0 \pm 1.55$ & $104.9 \pm 1.40$ & 0.3450 \\
\hline & DBP & $65.08 \pm 1.27$ & $67.44 \pm 1.77$ & 0.2283 \\
\hline
\end{tabular}

Note: Results are expressed as mean $\pm \mathrm{SD} \quad *_{\text {- significant }}$

\section{AUTHORS:}

1. Dabade Sheetal Kuldeep

2. Dabade Kuldeep J

\section{PARTICULARS OF CONTRIBUTORS:}

1. Assistant Professor, Department of Physiology, Institute of Medical Sciences and Research, Mayani, Maharashtra.

2. Assistant Professor, Department of Community Medicine, Institute of Medical Sciences and Research, Mayani, Maharashtra.

\section{NAME ADRRESS EMAIL ID OF THE} CORRESPONDING AUTHOR:

Dr. Dabade Sheetal Kuldeep,

Shiv Shakti Colony, Gut Number 91, A/P Jasingpur, Tal - Shirol,

Dist - Kolhapur (416101), Maharashtra.

Email-drsheetal_sapna@yahoo.com

Date of Submission: 19/11/2013.

Date of Peer Review: 20/11/2013.

Date of Acceptance: 02/12/2013.

Date of Publishing: 11/12/2013 